\title{
Observations on sensory and sympathetic function during intrathecal analgesia
}

\author{
P. W. NATHAN ${ }^{1}$ \\ From the The National Hospital for Nervous Diseases, Queen Square, London
}

SYNOPSIS A dilute solution of procaine in glucose solution was injected by slow drip into the lumbar theca of patients to cause a differential block. Vasodilatation of the skin vessels of the lower limbs always occurred before any change in sensibility. The first changes in sensibility were inability to feel painful stimuli and warm stimuli; these two forms of sensibility were usually coextensive and occurred at the same time. When this was not so, either form of sensibility could be more extensively disturbed than the other. When warmth sensibility was removed, cold sensibility was either normal or diminished or cold stimuli caused non-thermal sensations such as non-thermal wetness or pressure. It is concluded that the nerve fibres signalling warmth are the smaller delta fibres or non-myelinated fibres or both. As two groups of investigators who recorded from the non-myelinated fibres in man found no non-myelinated fibres responding to cold, it is concluded that fibres signalling cold cover the same delta range as those signalling warmth, together with a proportion of larger delta fibres.7 When fibres subserving pain, warmth, and cold were blocked, tactile sensibility could be normal. Ite is concluded that, if there are tactile fibres in man in the smaller delta and non-myelinated ranges, $\stackrel{\mathbb{P}}{\rightarrow}$ 응 their contribution to tactile sensibility is insignificant. It is also concluded that the pre-ganglionico B fibres are the most susceptible of all fibres of the nerve roots to local anaesthetic agents. On two occasions, piloerection occurred when the pre-ganglionic sympathetic fibres were blocked. In two patients spontaneous itching occurred when all peripheral nerve fibres were blocked except large tactile fibres.

The knowledge that we have about the peripheral nerve fibres that subserve various kinds of cutaneous sensibility is derived from various sources; and some of it comes from blocking the fibres of the posterior nerve roots by local anaesthetic solutions. This evidence has shown that the fibres are blocked in the order of those subserving pain first and those subserving tactile sensibility last. The evidence derived from this source is incomplete, for two questions remain unanswered. It is not certain where the fibres subserving thermal sensation come in the order of block; and, among the fibres reporting change in skin temperature (thermoreceptors), it is uncertain whether warm or cold receptors are blocked first. Although most investigators have found that pain sensibility is removed before warmth sensibility, not everyone agrees with this. Heinbecker et al. (1934), for instance, found that thermoreceptors were blocked before the fibres

1 Member of the external scientific staff, Medical Research Council. (Accepted 26 August 1975.) reporting pricking and pressure pain. Landau et al. (1960) found with epidural analgesia that most subjects had 'pinprick, heat and cold sensation affected simultaneously and to a similar degree in identical segments'. When there was any difference, 'any of the three modalities might be more affected than any other'.

At the time when these studies on sensory dissociation with differential blocking procedures were done, it had not been firmly established that the peripheral nerve fibres were stimulus-specific. For example, it was thought at the time that all non-myelinated fibres were nociceptors and were concerned in signalling pain. Even if all investigators had agreed on the facts, the conclusions drawn from them might well have been wrong. Finding out which fibres normally subserve which forms of sensibility has not been easy, and evidence coming from many different sources is valuable. The evidence has come from blocks with local anaesthetics, ischaemic blocks, cold blocks, it has been obtained from experi- 
ments in animals, and recently, and most important, it has been obtained from directly recording activity in nerve fibres in man while stimuli are applied to the skin. The opportunity arose of studying cutaneous and deep sensibility when it was decided to give a dilute anaesthetic solution intrathecally before treating spasticity with intrathecal phenol solution. It was thought that this evidence would be useful as the differential action of local anaesthetics is now better understood. Evidence obtained could then be correlated with recent work on the peripheral nerve fibres and modalities of sensation in the monkey.

When the fibres of the posterior roots are differentially blocked in man by a dilute local anaesthetic solution and when these data are used to learn which fibres subserve which kinds of sensibility, some facts are taken as known, but they may not be sufficiently known to everybody. It seems desirable to set these out here.

1. Normal sensibility depends on the activity of an adequate number of stimulus-specific peripheral nerve fibres. If this number be inadequate, there will be some kind of disturbance in sensibility, but this disturbance will not necessarily take the form of a diminution in that kind of sensibility. Further, if a kind of sensibility depends normally on an input in two sorts of fibre-say, small myelinated and non-myelinated-and one of these sorts is blocked, one cannot forecast in what manner sensibility will be disturbed. The same argument applies when a proportion of myelinated fibres of a certain size are blocked while myelinated fibres of another size remain active. And further, two people experiencing the same proportion of fibres blocked may not have the same sensation or may not report it in the same words. Normal sensation is based on learning. A sensation not previously experienced may be reported on differently by different people.

2. Peripheral nerve fibres are stimulus-specific. In all mammalian species in which the subject has been investigated, the larger fast-conducting fibres are mechanoreceptors. There are also mechanoreceptors among small delta myelinated and the non-myelinated fibres. What is known at present with regard to thermoreceptors will be reviewed in the discussion.

3. Nathan and Sears $(1961,1962)$ showed that dilute anaesthetic solutions block the very smallest myelinated fibres earlier and at lower concentrations than non-myelinated fibres. They showed that fibres with different modes of conduction, the $\mathrm{A}, \mathrm{B}$, and $\mathrm{C}$ fibres, cannot be fitted into one order of block, based on fibre size. The kind of blocking that consists of total blocking of fibres of one size while leaving fibres of larger size unaffected, they called absolute differential block.

Observations on the differential blocking and unblocking of spinal root fibres by spinal and epidural anaesthetic solutions will be reported here. Most attention will be paid to thermal sensibility. The motor effects of these anaesthetic solutions have been published (Nathan, 1968).

\section{METHODS}

PATIENTS The following patients were studied: six patients with disseminated sclerosis with spinal type of paraparesis; one patient with familial paraplegia; one patient with hemiplegia due to thrombosis of the right middle cerebral artery; one patient with postherpetic neuralgia; one patient with carcinoma of the prostate; one patient with lymphoepithelioma of the nasopharynx with metastases in the left iliac crest and acetabulum. Two patients with sciatica had the anaesthetic solution injected epidurally.

Although not all the patients had normal sensibility, the diminution in sensibility that some had did not interfere with the results obtained during spinal anaesthesia.

TECHNIQUE The dilute anaesthetic solution was given as a preliminary investigation before treating these patients by giving phenol solution intrathecally.

ANAESTHETIC SOLUTION FOR SPINAL ANAESTHESIA The concentration of anaesthetic was based on the studies of Sarnoff et al. (1946), and of Nathan and Sears. The solutions used were procaine $0.2,0.24$, or $0.3 \%$ in $6 \%$ glucose solution. Effects obtained were not due to the hyperosmolarity of the solution, as the same effects were obtained in one patient in whom the anaesthetic was dissolved in Ringer-Locke solution. The amount of intrathecally injected solution was 20 to $30 \mathrm{ml}$. The patient was placed on his side so that the vertebral column made an angle of about $25^{\circ}$ with the horizontal, with the head up. The solution was dripped into the theca at rates between 1 and $5 \mathrm{ml} / \mathrm{min}$. The spinal puncture was between the 4th and 5th lumbar vertebrae.

ANAESTHETIC SOLUTION FOR EPIDURAL ANAESTHESIA The solution used was piperocain hydrochloride 
$1.5 \%$. The solution was not made more dilute as it was being used in these patients therapeutically for the pain of sciatica. The epidural injection was through the sacrococcygeal foramen.

METHODS OF EXAMINATION AND RECORDING Not all the methods of examination could be applied in each patient, for, differential blocking of nerve fibres being a passing phase, the time for examination was short. Sensory stimuli were applied for long enough for the patient to be satisfied that he had made a good judgment; there was no time limit. No attention was paid to small degrees of changes in sensibility. Tactile sense was examined by asking the patient to note any differences when large areas of skin were rubbed or stroked with cotton wool. Passive movements of the toes and feet were tested in the usual clinical way and sensation of a vibrating fork was tested to a fork of $256 \mathrm{~Hz}$. Cutaneous pain was tested by repeated pin prick and by a radiant heat source held near the skin for a length of time adequate to cause pain. Thermal sensibility was tested in two ways: one way was designed to exclude tactile stimulation and to excite only thermoreceptors; the other way was to use a thermal stimulus that did deform the skin, for in normal living a hot or cold stimulus to the skin is usually a hot or cold object touching the skin. The thermal contact stimulus was a brass cylinder of $3 \mathrm{~cm}$ diameter containing water at various temperatures; on some occasions a block of ice was also used. The purely thermal warmth stimulus was the radiant heat source, moved around over an area of skin of several square centimetres. The purely thermal cold stimulus consisted of spraying ethyl chloride on aluminium foil spread flat on the skin. The patient lay with his upper limbs lying at his sides; and so stimuli could be applied easily to both the hands and forearms and the thighs, the upper limb acting as a control for the lower. Vasomotor activity was examined by thermocouples on the toes and finger-tips; blood pressure was taken intermittently by a sphygmomanometer cuff.

\section{RESULTS}

SPINAL ANAESTHESIA Effects common to all patients 1. The first event was a rise in skin temperature of the toes and feet (when the block was cranial enough to include the 2 nd and 1st lumbar roots). This rise in temperature was always felt by the patients, who reported that their feet were getting warmer. Thus there was no marked change in thermal sensibility at the time when the vasomotor fibres were blocked; there was always a clear-cut interval between the full vasodilatation and the onset of any change in sensibility.

2. Within two or three minutes of blocking of the vasomotor fibres, the fibres subserving pain and warmth were blocked. These two forms of sensibility were usually blocked at about the same time and in the same dermatomes. There were small variations, perhaps due to the fact that painful and thermal stimuli were not of equivalent intensity. On rare occasions, and more often during recovery from the anaesthesia, the areas of inability to feel painful and to feel warm stimuli were not coextensive, either one being present without the other. On these occasions, a radiant heat stimulus might cause no sensation of warmth but with longer presentation it would cause a sensation of hot-pain. This could be in a place where no pain could be felt with pinprick. Also, in areas where pain sensibility was removed, warm stimuli might cause an abnormal thermal sensation but no sensation of warmth.

3. There was a clear-cut differential blocking between the fibres subserving tactile sensibility and all other fibres. In many cases, no changes were found in tactile sensibility. When it was affected, this was always many minutes after other forms of sensibility had been obliterated. There were no other effects common to all patients.

Different effects in individual patients With regard to warmth and cold, this could not be tested in one of the patients, as warmth sensibility was too much affected by the disseminated sclerosis for the testing to be reliable. In any patient, the differential loss of pain and warmth sensibility was not necessarily the same during the induction of anaesthesia and during recovery. Nor was it the same throughout all dermatomes. For example, in an observant and intelligent student, cold was felt normally throughout the dermatomes where pain and radiant heat could not be felt. But, on the boundary area between normal sensibility and absence of pain and warmth sensibility, the ethyl chloride spray caused no sensation of cold but a sensation of liquid without a temperature component.

The commonest observation was that in the areas in which pain and warmth sensibility were removed, cold stimuli caused some sensa- 
tion but not the full and normal sensation of cold. They could also cause a sensation of warmth, or a feeling of liquid without a thermal component, or a vague feeling of pressure. When and where cold stimuli caused a sensation of warmth, warm stimuli caused no sensation. In some of the patients, cold stimuli caused a fully normal sensation of cold in regions where warmth and pain sensibility were removed. In a similar number of cases, the loss of cold sensibility was the same as the loss of pain and warmth sensibility.

During recovery from the block, cold sensibility usually recovered before warmth and pain sensibility.

Two patients were exceptional in that cold sensibility was removed before pain and warmth sensibility. In one a note was made at the time, saying 'It is very striking how she feels radiant heat immediately in the region where cold sensibility is absent'; this area was bilateral. In the other patient, there were some areas in which radiant heat caused a full sensation of heat and the ethyl chloride spray felt only slightly cold. In this patient, during recovery from anaesthesia, warmth sensibility returned before cold sensibility. The dermatomes in which pain of pinprick could not be felt were the same as those in which cold sensibility was lost.

In both of these patients intense spontaneous itching developed. It started in dermatomes in which tactile sensibility was normal and in which pain and cold could not be felt and warmth was either not felt or felt to a diminished degree. It continued during the recovery from anaesthesia, still being present in areas where thermal sensation had recovered fully and pain was felt fully or almost fully.

In one of these patients and in one other patient, at a time when there was full vasodilatation of the surface blood-vessels of the lower limbs, there was spontaneous contraction of the arrectores pili muscles of the skin of the lower limbs. In one of these patients, it occurred during a great fall in blood pressure.

Conclusions regarding order of block of fibres subserving warmth and cold 1. Vasomotor fibres are blocked before any other fibres. At a time when these fibres are blocked, the nerve fibres signalling warmth are unaffected. This was shown by all patients spontaneously observing the heating of their lower limbs.

2. When fibres subserving pain and those subserving warmth were blocked, those subserving cold were usually disturbed; but not all of them were blocked. Also observed but less commonly was that when pain and warmth could not be felt, cold was still felt normally. It was also found that the loss of pain, warmth, and cold was coextensive and occurred at about the same time. Rarely, cold sensibility was removed before pain and warmth sensibilities.

Conclusions regarding fibres subserving sensations other than warmth and cold 1. Pain and warmth sensibilities were always removed soon after vasodilatation of the skin vessels occurred.

2. Pain sensibility and warmth sensibility were usually removed at the same time and in the same dermatomes.

3. Pain induced by radiant heat and pain induced by repeated pinprick were not necessarily removed and did not necessarily recover simultaneously. That the response to these two forms of stimulation behaved differently with spinal anaesthesia does not appear to be a matter of different stimulus intensities.

4. In all cases there was a clear-cut differential anaesthesia, in that sensations induced by stroking with cotton wool, moving one or two hairs, rubbing the skin, and vibrating forks were normal, whatever other forms of sensibility were lost.

5. A sensation of wetness could occur, when there was no thermal sensibility.

6. Spontaneous itching occurred in two patients when the only kind of sensibility remaining was tactile. It continued unchanged at a time when radiant heat caused warmth and when pinprick caused slight pain.

7. The arrectores pili muscles in two patients showed a massive contraction at a time when there was full cutaneous vasodilatation. At this time, one of the patients had a blood pressure of 90/60 mm Hg.

\section{DISCUSSION}

The order of block seen in these experiments was first vasomotor fibres, then nociceptor and thermoreceptor fibres. Absolute differential 
block occurred only in the form that no tactile fibres were blocked at a time when all small fibres were blocked. These results agree better with those of Landau et al. (1960) than with those of other workers, although they are not exactly the same. They found that 'pinprick, heat and cold sensation were affected simultaneously and to a similar degree' only rarely; but they did find that fibres subserving pain and warmth were usually blocked before those subserving cold.

Questions concerning the order of block of all fibres, the order of block of fibres subserving different kinds of thermal sensibility, and the relative order of block of fibres subserving warmth and cold will now be considered.

VASOMOTOR AND PILOMOTOR FIBRES As full vasodilatation occurred before any change in sensibility, it is concluded that the preganglionic sympathetic fibres were blocked before an appreciable number of afferent fibres of any group. These are B fibres. It is only very recently that the order of block of these fibres in relation to $\mathrm{C}$ and $\mathrm{A}$ fibres has been found out. Heavner and de Jong (1974) examined this question by applying various concentrations of lignocaine to the cervical sympathetic trunk of the rabbit, a nerve that contains preganglionic $B$ fibres and postganglionic $\mathrm{C}$ fibres. They found that a $500 \mu \mathrm{mol}$ solution blocked all the B fibres in 15 minutes; it did not block all $\mathrm{C}$ fibres in 30 minutes. Their total work showed that 'the B fibres are about three times more sensitive to lignocaine than are the $\mathrm{C}$ fibres'. The diameter of the B fibres of the rabbit's cervical trunk is 1-3 $\mu \mathrm{m}$; and the diameter of the human preganglionic fibres of the 1st and 2nd lumbar roots, according to Pick and Sheehan (1946) is $2-3 \mu \mathrm{m}$. In the cases reported here, there was total block of sympathetic fibres to the lower limbs before any change in sensibility could be detected. If, in man, these $B$ fibres have the same safety factors as $\mathrm{A}$ fibres with the same conduction rates and are of the same size, then B fibres and the smallest delta fibres would be blocked at the same time. The results obtained here showed that the smallest delta fibres were conducting when all B fibres were blocked. And so it is concluded that the $B$ fibres in man are more sensitive to the action of local anaesthetics than the smallest $A$ fibres. And as the smallest A fibres are more sensitive to anaesthetics than C fibres, it is concluded that the $\mathrm{B}$ fibres are also more sensitive than the $\mathrm{C}$ fibres.

In two patients there was an intense piloerection at a time when the preganglionic sympathetic fibres were blocked. It must be concluded that the arrectores pili muscles were not being excited by their nerves. Presumably they were being excited by circulating noradrenaline, released, no doubt, owing to the large fall of blood pressure. This piloerection remained obvious for two hours after the patient had been laid flat and the blood pressure had returned to a normal level.

THERMORECEPTORS A criticism of the method used here might be that warm and cold stimuli have not been made equivalent in intensity. But the sensation of temperature is related not so much to differences above and below skin temperature as to differences from the threshold at which any change in temperature is first felt. The stimuli used were supramaximal to such an extent that any consideration of relative difference of intensities of stimuli from threshold or relative distances from the skin temperature became unimportant. And so a criticism of the finding that cold stimuli were felt less and later than warm stimuli was due to its being a stronger stimulus is considered to be invalid.

Although slowly adapting mechanoreceptors in the macaque are excited by strong cooling of the skin, Johnson et al. (1973) showed that "this fiber population serves a purely "tactile" function and that its responsiveness to changes in skin temperature is of "nuisance value" only'. They also showed that the suppressive action of warmth on cold fibres and of cold on warm fibres is unlikely 'to signal useful information to the central nervous system' for thermal sensory discrimination.

The conclusion arrived at from the investigation reported here is that there is no invariable order of blocking and unblocking of the fibres signalling warmth and fibres signalling cold. This fact accounts for the various reports given by other investigators that are to be found in the literature. The commonest finding was that when warm receptors were blocked to such an extent that no warm stimuli could be felt, a 
large number of cold receptors were blocked, but sufficient remained conducting to give rise to some kind of sensation. On occasions, a lesser number of cold receptors were blocked, and cold sensibility was normal when all fibres subserving pain and warmth were blocked; and on other occasions fibres subserving pain, warmth, and cold were all blocked at the same time. On a very few occasions, cold receptors were blocked before fibres subserving warmth and pain.

If we now consider the fibres in relation to the action of dilute anaesthetic solutions, we conclude that there must be a great overlap of the fibres signalling warmth and cold, and that some fibres signalling cold remain unblocked when all fibres signalling warmth are blocked; there is also some evidence that fibres signalling warmth can remain unblocked when all fibres signalling cold are blocked.

The evidence obtained by investigators who were able to carry out direct recordings from nerve fibres in the monkey and man will now be summarized. It must be stated that one has no right to assume that the nerve fibres will be the same size and belonging to the same groups in man as in the monkey. The macaque is a small animal no larger than a cat; the baboon, particularly the male, is considerably larger. There is evidence that functions in a small animal are carried out by smaller nerve fibres than the nerve fibres carrying them out in larger animals.

In the macaque and baboon, fibres signalling cold were found to conduct at rates between 3.6 and $15 \mathrm{~m} / \mathrm{s}$ by Iggo (1969); this puts them within the smallest delta range. Iggo also found three non-myelinated fibres activated by cold, with the same properties as the delta fibres. In a later investigation, in the macaque, Hensel and Iggo (1971) found that a third of the cold receptors were among the smallest delta fibres and twothirds were non-myelinated fibres. In the median and ulnar nerves of the macaque, Lamotte (1972) found that the fibres signalling cold were delta fibres conducting at a rate of $15 \mathrm{~m} / \mathrm{s}$. In the same species, Darian-Smith et al. (1973) found cold thermoreceptors with conduction rates throughout the delta fibre range, with a mean of $15 \mathrm{~m} / \mathrm{s}$. This group and Lamotte did not investigate non-myelinated fibres. Long (1973), also investigating the macaque, found cold thermoreceptors conducted at rates of 13 to $15 \mathrm{~m} / \mathrm{s}$, hence small delta fibres.

The recording from single fibres of peripheral nerves in man by means of an electrode introduced through the skin into the nerve was introduced by Hagbarth and Vallbo (1967). A further development of the technique was worked out by Hallin and Torebjörk (1970), Torebjörk and Hallin (1970), Van Hees and Gybels (1972), and Torebjörk (1974); they succeeded on many occasions in recording the activity of nonmyelinated fibres. This direct way of investigating which nerve fibres subserve which forms of sensibility may perhaps be said to make any indirect way of investigating the matter of little interest. But even this method may not be as definitive as one first thinks. It may be, for instance, that the activity of one thermoreceptive fibre does not supply enough information to the central nervous system; it may be that many fibres have to be simultaneously active and that this input has to be integrated within higher levels of the central nervous system before the subject can conclude that the temperature of a local area of skin has been raised or lowered.

In fact, Van Hees and Gybels (1972) never found any non-myelinated fibres of the superficial radial nerve that were excited by ice or ether on the skin. And Torebjörk (1974) found that cooling the skin from $29^{\circ}$ and $33^{\circ}$ to between $23^{\circ}$ and $19^{\circ}$ was 'with two exceptions' an ineffective stimulus for non-myelinated fibres. The two exceptions were polymodal nociceptors; they did fire with a falling temperature.

Summarizing this work, we conclude that in the monkey the fibres signalling cold are delta fibres with a mean conduction rate of $15 \mathrm{~m} / \mathrm{s}$. One group of investigators found delta fibres signalling cold throughout the total range of delta fibres, another group found they were only the smallest delta fibres. Most investigators did not examine non-myelinated fibres; but Hensel and Iggo (1971) found that two-thirds of coldsignalling fibres were non-myelinated. In man, the little amount of evidence there is shows that non-myelinated fibres do not signal cold.

With regard to fibres signalling warmth in the monkey, nearly all evidence shows that they are non-myelinated. This was found by Iggo and Ogawa (1971), Hensel and Iggo (1971), Lamotte 
(1972), and Darian-Smith et al. (1973). Iggo and Ogawa found a few of the slowest conducting delta fibres behaving as warmth receptors. Although evidence concerning non-primates is not being considered here, it must be noted that recently Martin and Manning (1969, 1972) showed that, in the cat, there are warm receptors in the smallest delta range as well as among non-myelinated fibres. The conduction rates of these fibres in the saphenous nerve were 0.85$1.3 \mathrm{~m} / \mathrm{s}$ among the non-myelinated fibres, and $10-19 \mathrm{~m} / \mathrm{s}$ among the myelinated fibres.

In man, Van Hees and Gybels (1972) found that the non-myelinated fibres were fired by raising the local skin temperature to $41^{\circ} \mathrm{C}$; this temperature causes a sensation of warmth. Other non-myelinated fibres were fired by higher temperatures, 'by thermal radiation, strong enough to be termed heat'; when this stimulus was prolonged, it caused pain. Torebjörk (1974) found that heating the skin from $40^{\circ}$ to $45^{\circ}$ excited these fibres. Torebjörk and Hallin (1974) wrote that moderate warming did not excite non-myelinated fibres; but 'a burning match placed as close to the receptive field as to be perceived by the subject as pain initiated a vigorous burst of impulses'.

Using the principles of the order of block of fibres of the roots by anaesthetic solutions obtained by Nathan and Sears $(1961,1962)$ and taking the evidence obtained from recording from single nerve fibres, we can draw conclusions regarding the fibres that are warmth and cold thermoreceptors in man. In this investigation fibres signalling warmth and fibres signalling noxious stimulation causing pain were of the same range. As it is known that fibres signalling noxious events are small delta and nonmyelinated fibres, the fibres signalling warmth were fibres of either or both of these groups. With dilute anaesthetic solutions, these two groups of fibres might be blocked at about the same time or else the small delta fibres would have been blocked before all the non-myelinated fibres. Larger delta fibres would have been blocked later than small delta and nonmyelinated fibres. The fact that cold sensibility was usually present or present to a certain degree when pain and warmth sensibilities were absent indicates that there are some large fibres signalling cold; but a larger proportion of them must be of the same range as those signalling warmth.

In an investigation of sensation, psychophysical aspects of the subject need to be taken into account. Sensation is to a greater or lesser extent a matter of interpretation. It is particularly with thermal sensation that even under normal conditions there are paradoxical sensations and uncertainties in interpretation. In the literature of nerve blocking, it is particularly with differential blocking of the two kinds of thermoreceptors that discrepancies and difference of opinion occur.

One of the questions requiring an answer is how many of the fibres usually used for feeling a certain sensation are a sufficient number to recognize that sensation. It was sometimes observed among these patients that once a cold stimulus had been clearly recognized as suchsay, in the 4th lumbar dermatome-then it was recognized when applied afterwards in the 5th lumbar dermatome, where it had previously been felt as warm. This observation suggests that a subject might have had difficulties in making a decision when there was a certain proportion of thermoreceptors blocked; once he had recognized the nature of the stimulus in a region where more data were available, he was able to make a firmer decision in the area from which there were insufficient data. It is suggested that when a cold stimulus caused a sensation of warmth or a sensation other than cold or a sensation of slight cold, it was exciting fibres normally signalling a fall in skin temperature but an insufficient number of them to inform the subject that the stimulus was fully cold. Even under normal conditions, a judgment of cold or hot is helped when the area of stimulation is increased and thus when more receptors are excited; this is not so with tactile and far less so with noxious stimulation.

FIBRES SUBSERVING TACTILE SENSIBILITY DarianSmith et al. (1973) found in the monkey's median nerve that there were tactile fibres conducting around $22 \mathrm{~m} / \mathrm{s}$, and that 'their average axon diameters were larger than those of the thermoreceptor group'. This places them among the smaller delta group, with a probable diameter of 1-4 $\mu \mathrm{m}$, in agreement with the findings of most investigators. If there are such 
fibres in man, they would have been blocked. In fact, when pain and warmth and cold could not be felt, there was no change in tactile nor in subcutaneous sensibility; even moving one or two hairs of the skin was felt.

Now that recordings from non-myelinated fibres have been made in man, Van Hees and Gybels and Hallin and Torebjörk have found that there are $\mathrm{C}$ fibre mechanoreceptors; they are activated not by light touch but by von Frey hairs weighing 5-6 g. They looked for but did not find $\mathrm{C}$ fibres responding to touch lighter than this. Torebjörk and Hallin (1974) found that these fibres were not excited by cottonwool, by puffs of air, by bending hairs, or by stretching the skin. The results obtained here indicate that if there are such $\mathrm{C}$ fibre mechanoreceptors in man, their contribution to cutaneous sensibility is unimportant, for no changes in sensibility were found when these fibres, if they exist, were blocked.

SPONTANEOUS ITCHING In two patients itching occurred spontaneously. That in itself is curious - that it occurred in only two out of 15 patients. Normally, itch occurs from stimulation of the superficial dermis and the epidermis. It may occur with lesions of the posterior root ganglia with much sensory loss, as after herpes zoster. Itch, spontaneous and induced, is reported to the central nervous system by non-myelinated fibres (Hardy et al., 1952). Yet, in the two patients in whom it occurred, it came on when all afferent fibres except the large tactile fibres were blocked. One must envisage that itching can start spontaneously within the spinal cord, when a large number of peripheral afferent fibres are blocked, leaving just a few large tactile fibres intact.

I take this opportunity of thanking Dr Martin Halliday for his help with some of the experiments and Dr Marion C. Smith and Professor T. A. Sears for advice in writing the paper.

\section{REFERENCES}

Darian-Smith, I., Johnson, K. O., and Dykes, R. (1973) 'Cold' fiber population innervating palmar and digital skin of the monkey: responses to cooling pulses. Journal of Neurophysiology, 36, 325-346.

Hagbarth, K-E., and Vallbo, A. B. (1967). Mechanoreceptor activity recorded percutaneously with semi-microelectrodes in human peripheral nerves. Acta Physiologica Scandinavica, 69, 121-122.
Hallin, R. C., and Torebjörk, H. E. (1970). Afferent and efferent $\mathrm{C}$ units recorded from human skin nerves in situ. Acta Societatis Medicorum Upsaliensis, 75, 227-281.

Hallin, R. G., and Torebjörk, H. E. (1974). Unmyelinated nerve fibres in man. In Advances in Neurology, vol. 4, pp. 19-27. Edited by J. J. Bonica. Raven Press: New York.

Hardy, J. D., Wolff, H. G., and Goodell, H. (1952). Pain Sensations and Reactions. Ballière, Tindall, and Cox: London.

Heavner, J. E., and de Jong, R. H. (1974). Lidocaine blocking concentrations for B and C nerve fibers. Anesthesiology, 40, 228-233.

Heinbecker, P., Bishop, G. H., and O'Leary, J. (1934). Analysis of sensation in terms of nerve impulse. Archives of Neurology and Psychiatry, 31, 31-53.

Hensel, H., and Iggo, A. (1971). Warm and cold fibres in primates. Pflügers Archiv für die gesamte Physiologie, 324, 1-8.

Iggo, A. (1969). Cutaneous thermoreceptors-primates and subprimates. Journal of Physiology, 200, 403-430.

Iggo, A., and Ogawa, H. (1971). Primate cutaneous thermal nociceptors. Journal of Physiology, 216, 77-78P.

Johnson, K. O., Darian-Smith, I., and Lamotte, C. (1973). Peripheral neural determinants of temperature discrimination in man: a correlative study of responses to cooling skin. Journal of Neurophysiology, 36, 347-370.

Lamotte, C. (1972). The Sensation of Warmth: Peripheral Neural Mechanism. Thesis: Johns Hopkins University.

Landau, W. M., Weaver, R. A., and Hornbein, T. F. (1960). Fusimotor nerve function in man: differential nerve block studies in normal subjects and in spasticity and rigidity Archives of Neurology, 3, 32-45.

Long, R. R. (1973). Cold fiber heat sensitivity: dependency of 'paradoxical' discharge on body temperature. Brain Research, 63, 389-392.

Martin, H. F., and Manning, J. W. (1969). Rapid thermal cutaneous stimulation: peripheral nerve responses. Brain Research, 39, 524-526.

Martin, H. F., and Manning, J. W. (1972). Response of A delta fibers of peripheral nerve to warming of cutaneous fields. Brain Research, 43, 633-656.

Nathan, P. W. (1968). Motor effects of differential block of spinal roots in spastic patients. Journal of Neurological Sciences, 8, 19-26.

Nathan, P. W., and Sears, T. A. (1961). Some factors concerned in differential nerve block by local anaesthetics. Journal of Physiology, 157, 565-580.

Nathan, P. W., and Sears, T. A. (1962). Differential nerve block by sodium-free and sodium-deficient solutions. Journal of Physiology, 164, 375-394.

Pick, J., and Sheehan, D. (1946). Sympathetic rami in man. Journal of Anatomy, 80, 12-20.

Sarnoff, S. J., Arrowood, J. G., and Chapman, W. P. (1946). Differential spinal block. Surgery, 20, 150-159.

Torebjörk, H. E. (1974). Afferent C units responding to mechanical, thermal and chemical stimuli in human nonglabrous skin. Acta Physiologica Scandinavica, 92, 374-390.

Torebjörk, H. E., and Hallin, R. G. (1970). C fibre units recorded from human sensory fascicles in situ. Acta Societatis Medicorum Upsaliensis, 75, 81-84.

Torebjörk, H. E., and Hallin, R. G. (1974). Identification of afferent $C$ units in intact human skin nerves. Brain Research, 48, 397-400.

Van Hees, J., and Gybels, J. M. (1972). Pain related to single afferent $C$ fibres from human skin. Brain Research, 48, $397-400$. 